OPEN ACCESS

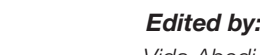

Vida Abedi,

Geisinger Health System,

United States

Reviewed by:

Nicolò Merendino,

Università degli Studi della Tuscia, Italy

Hailong Song,

University of Pennsylvania

United States

*Correspondence:

Md. Ashraful Alam

sonaliagun@yahoo.com

Specialty section:

This article was submitted to

Nutritional Immunology,

a section of the journal

Frontiers in Nutrition

Received: 07 November 2018

Accepted: 23 July 2019

Published: 07 August 2019

Citation:

Alam MA (2019) Anti-hypertensive Effect of Cereal Antioxidant Ferulic Acid and Its Mechanism of Action.

Front. Nutr. 6:121.

doi: 10.3389/fnut.2019.00121

\section{Anti-hypertensive Effect of Cereal Antioxidant Ferulic Acid and Its Mechanism of Action}

\author{
Md. Ashraful Alam* \\ Department of Pharmaceutical Sciences, North South University, Dhaka, Bangladesh
}

Ferulic acid is a simple phenolic acid found mainly in cereals and grains, used as an antioxidant and food preservative. Recent evidence suggests that ferulic acid possess anti-inflammatory, anti-diabetic, anticancer, and cardioprotective properties. Several investigations also have shown that ferulic acid rich food might prevent hypertension. As a potent scavenger of free radicals (ROS, reactive oxygen species), ferulic acid attenuates oxidative stress, which is responsible for lowering elevated blood-pressure through improved endothelial function and increased bioavailability of the nitric oxide in the arterial vasculature. This review article describes the role of ferulic acid in the pathophysiology of vascular dysfunction and hypertension along with highlighted the merit of further scientific and clinical exploration.

Keywords: ferulic acid, hypertension, endothelium, reactive oxygen species, NADPH oxidase

\section{INTRODUCTION}

Ferulic acid is a phenolic compound which is also known as a hydroxy-cinnamic acid derivative. Other compounds of this family include cinnamic acid, $p$-coumaric acid, caffeic acid, chrlorgenic acid, rosmarinic acid, and curcumin. Ferula foetida is the source of 3-methoxy-4-hydroxycinnamic acid which was isolated first by Austrian chemist Hlasiwetz Barth (1). Ferulic acid forms a structural component of lignocelluloses with dihydroferulic acid by cross linking lignin and polysaccharides which provides cell wall rigidity. Rice, wheat and oats, etc. are the major source of ferulic acid $(1,2)$. Other sources of ferulic acid are fruits and vegetables $(1,2)$. 3-(4-hydroxy-3-methoxyphenyl)-2-propenoic acid is commonly known as ferulic acid. Other names are 3-methoxy-4-hydroxycinnamic acid, caffeic acid 3-methyl ether, and coniferic acid (1). In most vegetables and fruits such as in coffee, cabbage, celery, and carrots, ferulic acid is conjugated with hydroxyl acids like quinic acid. In grains, ferulic acid may form an ester with sterols; gamma-oryzanol is one well-known example of this kind. Fifty to ninety percent of free ferulic acid is present in some vegetables such as burdock, water dropwort, and eggplant $(3,4)$. However, $0.1-0.5 \%$ free ferulic acid is present in cereals (4).

Ferulic acid is well-known for its antioxidant properties. Though ferulic acid was first isolated in 1866, its chemical synthesis procedure was discovered later in 1925 (1). Antioxidant properties of ferulic acid were first discovered by Japanese researchers in the extract from rice oil (5). Ferulic acid is used as a food additive antioxidant and food preservative in Japan (1). Chinese healers treat cardiovascular and cerebrovascular diseases using sodium ferulate, a salt of ferulic acid (6). The phenolic nucleus and carboxylic side chain present in the ferulic acid form a resonance stabilized phenoxy radical, which is responsible for the free radical-scavenging effect $(1,7)$. 
In recent years, epidemiology investigations revealed the health benefits of ferulic acid-rich foods and drinks. Consumption of cereals, fruits, and vegetables are beneficial to prevent cancer, diabetes and cardiovascular diseases $(8,9)$. Moreover, ferulic acid has been shown to prevent type 2 diabetes, obesity, and Alzheimer's disease (7, 10). Several preclinical investigations also showed that ferulic acid improved glucose metabolism, insulin action, and lowered lipid parameters $(11,12)$. Investigations have also demonstrated that consumption of cereals and grains improved endothelial or vascular function and produced an anti-hypertensive effect (13). The presence of ferulic acid has been attributed to such biological effects, as an active component of cereals and grains. The purpose of this review is to highlight the health benefit of ferulic acid, mainly the effects and mechanisms of ferulic acid on hypertension and related disorder.

\section{FERULIC ACID ABSORPTION AND BIOAVAILABILITY}

One third of the total dietary intake of polyphenolic compounds is consumed as simple phenolic acids. Considerable variation in the dietary intake of phenolic acids is seen in various geographic regions. Scalbert and Williamson estimated that subjects consuming fruits, vegetables, and phenolic acidcontaining beverages in the daily diet, the daily intake of total polyphenols to be about 1,000 mg (14). Ferulic acid is absorbed relatively faster than another phenolic compound from the stomach (2). After absorption, ferulic acid is rapidly formed conjugation product in the liver with glucuronides, sulfate, and sulfoglucuronide (2) (Figure 1). Distribution of ferulic acid in the body after single administration is considerable. Orally administered ferulic acid was distributed $\sim 4 \%$ in gastric mucosa, $10 \%$ in blood pool and liver, kidney, and 53\% distributed in other tissues (2). However, free ferulic acid bioavailability is very low due to the rapid conjugation process in the liver (2). It is more bio-available than other dietary flavonoids and phenolics so far studied (15).

Ferulic acid is a relatively safe molecule having low toxicity. The $\mathrm{LD}_{50}$ value is $2,445 \mathrm{mg} \mathrm{kg} \mathrm{kg}^{-1}$ body weight in male and $2,113 \mathrm{mg} \mathrm{kg}^{-1}$ body weight in female rat (16).

\section{ANTIOXIDANT EFFECT OF FERULIC ACID}

Ferulic acid showed strong antioxidant properties. The phenolic ring gives it strong resonance stability and can accept the electron more easily from free radical. It is thus a direct scavenger of free radicals. Moreover, hydrogen peroxide, superoxide, hydroxyl radical and nitrogen dioxide free radicals are scavenged very well by ferulic acid. Nitric oxide and $\mathrm{ABTS}^{\bullet+}$ radical scavenging activity of ferulic acid are much better compared to caffeic acid (17). Hydroxyl radicals in a fenton reaction system were also scavenged almost completely by ferulic acid at a concentration of $250 \mathrm{mg} / \mathrm{L}$ (18).

Ferulic acid increases the antioxidant enzyme activity and function that are responsible for scavenging free radicals. It also inhibits free radicals producing enzymes in tissues. Previous studies showed that cardiac superoxide dismutase, glutathione peroxidase (GPx) and catalase (CAT) activities and mRNA expression were increased by ferulic acid and $p$-coumaric acid (19). Antioxidant enzyme activities were also increased in diabetic rats (11) and high fat diet fed mice (20). Another class of redox-sensitive inducible protein is heme oxygenase-1 (HO-1), that provides efficient cytoprotection against oxidative stress. Ferulic acid and its derivatives caffeic acid phenethyl ester (CAPE) and curcumin acts as a novel class of HO-1 inducer and protects cellular injury due to oxidative stress (21-23).

\section{ANTI-INFLAMMATORY EFFECT OF FERULIC ACID}

Inflammation and immune response are considered as the key regulatory factors for the development and progression of various chronic diseases, such as cancer, diabetes, rheumatoid arthritis, atherosclerosis, and cardiovascular diseases. Ferulic acid showed anti-inflammatory action in various experimental in vitro and in vivo models. The LPS-treated Raw 264.7 murine macrophage is widely used to study inflammation in vitro. Macrophages play a central role in inflammation and are responsible for the production of inflammatory mediators such as pro-inflammatory and inflammatory cytokines (24). Ferulic acid prevented the production of macrophage inflammatory protein-2 (MIP-2) from RAW264.7 in response to respiratory syncytial virus (RSV) infection (25). Ferulic acid and its derivatives isolated from corn also inhibited inducible nitric oxide synthase (iNOS) expression in lipopolysaccharide (LPS)-stimulated Raw 264.7 cells as well as inhibited nitric oxide (NO) production (26). Similar results were also reported previously showed that inflammatory mediators, e.g., prostaglandin $\mathrm{E}_{2}$ and tumor necrosis factor-alpha (TNF$\alpha$ ) production was decreased by ferulic acid and related ester derivatives (18) and inhibited iNOS expression and function in lipopolysaccharide stimulated cells $(27,28)$.

Moreover, NCX 2057, a nitric oxide (NO)-releasing derivative of ferulic acid, inhibited iNOS mRNA and protein expression (29). The in-vivo anti-inflammatory response of ferulic acid

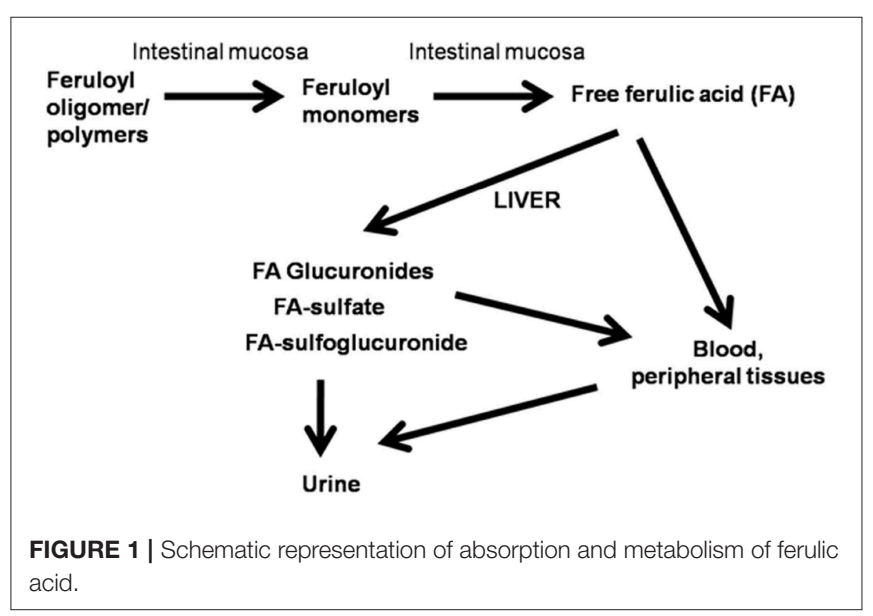


was also reported in nicotine treated rats. Nicotine-treated rats showed increased expression of cyclooxygenase -2 and NF- $\mathrm{B}$ in lung and liver which were reduced by ferulic acid (20 mg/kg) (30).

\section{EFFECT OF FERULIC ACID ON DIABETES AND HYPERCHOLESTEROLEMIA}

Ferulic acid showed useful anti-diabetic activities (10). Blood glucose and plasma lipids were lowered successfully in STZ treated rats by ferulic acid $(28,31)$. In vitro intestinal alphaglucosidase and porcine pancreatic alpha-amylase inhibitory activity have been reported recently by ferulic acid (32). In diabetes, an inhibitor of the intestinal alpha-glucosidase enzyme could be a useful treatment. Protective effect of ferulic acid was also seen in STZ rats by improving the antioxidant enzyme function (11). A recent report suggests that ferulic acid may increase the secretion of insulin from the cultured beta cell (32) and adiponectin from adipocyte (33). Improvement of glucose metabolism may be also responsible for the improvement of the vascular function. Ferulic acid supplementation improved the blood pressure in diet induced obese rats (34) possibly by improving the blood cholesterol and glucose metabolism (20). Previous reports also showed that ferulic acid decreased the hepatic HMG-CoA reductase, cholesterol transferase (ACAT), and cholesterol esterifying enzymes in the liver and exerted plasma lipid-lowering activities in vivo (26).

Cholesterol, especially LDL oxidation may be a potential source of developing the vascular diseases in diabetes and obesity. Ferulic acid showed potential inhibitory effect on LDL oxidation in vitro (35). Anti-atherogenic effect of ferulic acid was also seen in apolipoprotein E-deficient (apo $\mathrm{E}^{-/-}$) comparison with clofibrate in mice fed with a western diet (36). Ferulic acid also decreased the levels of phospholipids, lipid peroxides, low density lipoprotein, and very low density lipoproteincholesterol in the serum of isoproterenol intoxicated rats (37). Moreover, ferulic acid showed a protective effect on diabetic nephropathy. Supplementation with ferulic acid significantly prevented the rise of TGF- $\beta 1$ mRNA expression in Otsuka LongEvans Tokushima Fatty (OLETF) diabetic rat's kidney; however, ferulic acid showed no significant effect on COX-2 or ICAM-1 mRNA expressions (38).

\section{EFFECT OF FERULIC ACID ON BLOOD PRESSURE IN ANIMALS}

Ferulic acid was used as an antihypertensive drug in Chinese medicine. The first antihypertensive effect of ferulic acid was reported in 2002 (39). Single dose $(50 \mathrm{mg} / \mathrm{kg})$ ferulic acid administration reduced the blood pressure of spontaneously hypertensive rats within the first hour and returned to the baseline within $6 \mathrm{~h}$ (39). This dose was comparable with captopril, an ACE inhibitor (dose $50 \mathrm{mg} / \mathrm{kg}$ ). A positive correlation was also found with the reduction of BP and plasma ferulic acid concentration (39). Long-term supplementation of ferulic acid also reduced high blood pressure in L-NAME, a nitric oxide synthase inhibitor, induced SHR rats (39). However, ferulic acid showed no discernable effect in normotensive control Wister Kyoto (WKY) rats. In another study, rice bran fraction, rich in ferulic acid, prevented the elevated blood pressure in stroke prone SHR rats (34). Moreover, rice bran fraction lowered the urinary 8-hydroxy-2'-deoxyguanosine (8-OHdG) in Stroke prone SHR rats (34).

\section{EFFECT OF FERULIC ACID ON VASCULAR FUNCTION}

Nitric oxide which may be produced from vascular endothelium, plays the crucial role in maintaining the vascular tone and blood pressure $(40,41)$. It is evident the excess free radical (ROS) generation is responsible for the development of endothelial dysfunction and hypertension (42-44). Excess free radical generation in vascular endothelium may scavenge the nitric oxide by forming more damaging peroxynitrile and reduces the NO bioavailability (44). The previous study showed that ferulic acid restored endothelial function in spontaneously hypertensive rat (SHR) aorta probably by enhancing the bioavailability of nitric oxide (NO) (45). This study also provided evidence that ferulic acid may relax the aorta even after the removal of the intact endothelium, which means a direct effect of ferulic acid on vascular smooth muscle cells (45). The endothelial independent vascular response was also evaluated by another group of the researcher. Chen et al. showed the vascular response is mediated via direct inhibition of the common pathway of smooth muscle contraction after $\left[\mathrm{Ca}^{2+}\right] \mathrm{i}$ increase by sodium ferulate (46). However, the direct vesoralaxant effect of sodium ferulate could also be mediated through the inhibition of PKC dependent contraction of smooth muscle (46). The hallmark signs of vascular diseases are the proliferation of VSMC with thickening of the intima and narrowing of the vessel lumen $(47,48)$. The previous study also suggested that vasodilators producing nitric oxide could inhibit the proliferation of rat aortic smooth muscle cells (49). Ang-II, an endogenous vasoconstrictor agent stimulates the VSMC proliferation and migration. Treatment with ferulic acid showed that VSMC proliferation due to angiotensin II was prevented in a dose-dependent manner (50). Later on, it was found that ferulic acid may potentially inhibit the Angiotensin converting enzyme (ACE), an enzyme facilitates the conversion of Ang-I to ANG-II (34).

\section{THE MOLECULAR TARGET OF FERULIC ACID TO TREAT HYPERTENSION}

How ferulic acid showed a beneficial effect on the cardiovascular system is not fully understood. Ferulic acid and its related derivatives have proven as a potent antioxidant and antiinflammatory agent. The reactive oxygen species generation in vasculature have a direct correlation of developing hypertension in human and experimental animal (Figure 2) $(43,44)$. NADPH oxidase system present in the vasculature is the major source of free radicals (44). Angiotensin II has a profound effect on NADPH oxidase. Angiotensin II stimulates the ROS generation via NADPH oxidase in SHR rats $(51,52)$ and DOCA-salt rats $(53)$ 


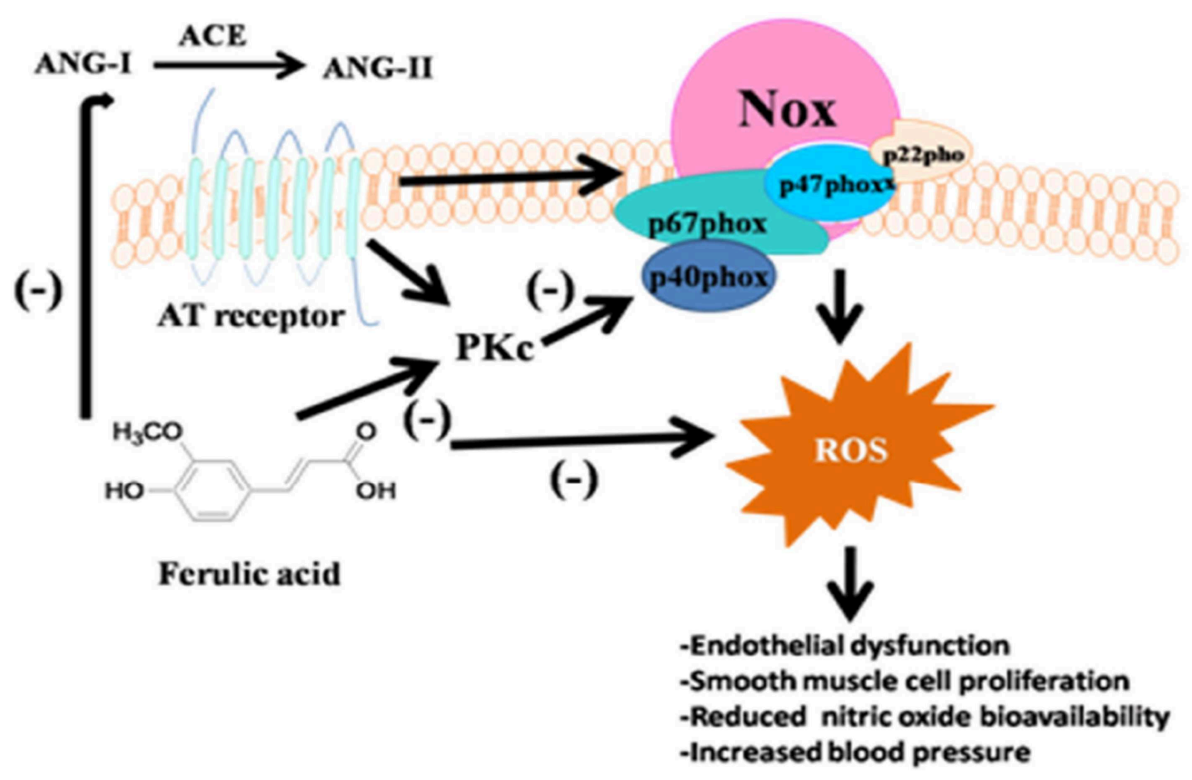

FIGURE 2 | Schematic representation on the effect of ferulic acid on vascular response and oxidative stress.

aorta. Suzuki et al. demonstrated that ferulic acid might inhibit the NADPH oxidase in SHR rat aorta (45). NADPH oxidase inhibitory activity may be evident as natural phenolic compound apocynine inhibits the NADPH oxidase. Interestingly, ferulic acid shares the core molecular structure of apocynine and thereby may acts as a non-selective $\mathrm{NAD}(\mathrm{P}) \mathrm{H}$ oxidase antagonist by reacting with sulfhydryl groups (54).

Another important target for ferulic acid might be the reninangiotensin aldosterone system. Previous in vitro and in vivo studies showed that ferulic acid inhibited angiotensin-converting enzyme activity $(34,55)$. Single oral administration of ferulic acid (9.5 mg kg-1) in SHRsp rats showed that systolic blood pressure (measured by tail-cuff method) was lowered below the baseline, which was correlated to the simultaneous reduction of plasma angiotensin-converting enzyme activity from 20.6 to $16.9 \mathrm{mU}$ $\mathrm{ml}^{-1}$ at $2 \mathrm{~h}$ (34).

Stress activated kinases are also involved in the proliferation and migration of VSMC. VSMC proliferation due to Ang-II stimulation is MAPK dependent. Several types of MAPK has been identified, ERK1/2, c-JUN kinase and P38 kinase system $(56,57)$. ERK1/2 and c-JUN kinase may directly be stimulated by ROS. Thus, it is evident that Ang-II mediated ROS generation may stimulate VSMC proliferation $(58,59)$. Ferulic acid inhibited the Ang-II mediated VSMC proliferation in a dose dependent manner (50). Ferulic acid also inhibited ERK1/2 and c-JUN kinase activity in VSMC after ANG-II exposure whereas the P38 MAP kinase was relatively unaltered (50). This study suggests that the inhibition of VSMC proliferation is mediated via ERK1/2 and c-JUN kinase mediated pathways.

Endothelium functions are regulated by the expression of specific genes in vascular endothelial cells. The physiologicallyrelevant concentration of polyphenol (ferulic acid, quercetin, and resveratrol) at a dose of $0.1 \mu \mathrm{M}$ were studied in cultured human umbilical vein endothelial cells (HUVEC), followed by measurement of gene expression by microarray and quantitative RT-PCR. This study suggested that these selected polyphenols up regulated 233 genes and down regulated 363 genes (60).

Transcriptional regulator of the vascular cell was also modulated by ferulic acid supplementation. Nrf-2 is a key transcriptional factor that activates the antioxidant-reactive element (ARE). Nrf-2 and ARE also regulates the expression of antioxidant Phase II detoxifying enzymes. Ferulic acid supplementation may increase cardiac $\mathrm{Nrf} 2$ protein expression in rats (19) which may induce the antioxidant enzyme such as HO1. Previously, we have discussed that ferulic acid may increase the antioxidant enzymes both in activity and mRNA level (19).

A recent investigation also reported that polyphenolics extract of whole wheat grains and ferulic acid protected doxorubicininduced cardio-toxicity in rat cardiomyocytes (61). This study suggested that, ferulic acid prevented the increased iNOS expression, NADPH oxidase activation, Nrf-2/HO-1 impairment in doxorubicin-induced rat cardiomyocytes (61).

\section{EFFECT OF FERULIC ACID ON CEREBRAL ISCHEMIA AND STROKE}

Cerebral ischemia is one of the deadly pathological conditions in which abrupt deprivation of oxygen and glucose is experienced by the brain tissues. As a result excessive production of free radicals, excess recruitment of inflammatory cells, and accumulation of intracellular calcium and initiation of apoptotic signals triggers ischemic damage to neuronal cells (62). Thus, antioxidants have been used for the development of neuroprotective drug in stroke therapy. Ferulic acid, as a small molecule, showed promising results (63). Previous study showed 
that rice bran extract supplemented with ferulic acid promoted functional recovery from ischemic injury in rat induced by middle cerebral artery occlusion (MCAO) (64). The reduction of cerebral infarct area and neurological deficit-score by ferulic acid treatment were at least partially attributed to the inhibition of superoxide radicals, and inhibition of inflammation by the reduction of ICAM-1 and NF- $\mathrm{KB}$ expression in transient MCAO rats (65). A recent study revealed that treatment with ferulic acid significantly attenuated memory impairment, and reduced hippocampal neuronal apoptosis and oxidative stress in a dose-dependent manner as well as inactivated $\mathrm{TLR}_{4}$ mediated inflammatory pathway (66). Protective effect of ferulic acid in neuronal apoptosis could be attributed to the activation of $\mathrm{p} 38$ MAPK mediated signal cascade which eventually inhibited the cytochrome c-mediated caspase-3-dependent apoptotic pathway (67). Nitric oxide (NO) acts as an important mediator in the brain and have both neuroprotective and neurotoxic effect in focal cerebral ischemia (68). Nitric oxide synthase proteins iNOS and nNOS expression levels have been seen increased during MCAO, and ferulic acid prevented the rise of these isoforms in rats (69).

\section{FUTURE DIRECTION}

Ferulic acid showed very promising activities on blood pressure regulation and modulated many of the known physiological system and molecular mechanisms. It is still not clear, how ferulic acid increased the bioavailability of nitric oxide in the

\section{REFERENCES}

1. Graf E. Antioxidant potential of ferulic acid. Free Radic Biol Med. (1992) 13:435-48. doi: 10.1016/0891-5849(92)90184-I

2. Zhao Z, Moghadasian MH. Chemistry, natural sources, dietary intake and pharmacokinetic properties of ferulic acid: a review. Food Chem. (2008) 109:691-702. doi: 10.1016/j.foodchem.2008.02.039

3. Sakakibara H, Honda Y, Nakagawa S, Ashida H, Kanazawa K. Simultaneous determination of all polyphenols in vegetables, fruits, and teas. J Agric Food Chem. (2002) 51:571-81. doi: 10.1021/jf0209261

4. Adom KK, Liu RH. Antioxidant activity of grains. J Agric Food Chem. (2002) 50:6182-7. doi: 10.1021/jf0205099

5. Yagi K, Ohishi N. Action of ferulic acid and its derivatives as antioxidants. J Nutr Sci Vitaminol. (1979) 25:127-30. doi: 10.3177/jnsv. 25.127

6. Wang BH, Ou-Yang JP. Pharmacological actions of sodium ferulate in cardiovascular system. Cardiovasc Drug Rev. (2005) 23:161-72. doi: 10.1111/j.1527-3466.2005.tb00163.x

7. Srinivasan M, Sudheer AR, Menon VP. Ferulic Acid: therapeutic potential through its antioxidant property. J Clin Biochem Nutr. (2007) 40:92-100. doi: 10.3164 /jcbn.40.92

8. Liu RH. Whole grain phytochemicals and health. J Cereal Sci. (2007) 46:20719. doi: $10.1016 /$ j.jcs.2007.06.010

9. Fardet A. New hypotheses for the health-protective mechanisms of wholegrain cereals: what is beyond fibre? Nutr Res Rev. (2010) 23:65-134. doi: 10.1017/S0954422410000041

10. Barone E, Calabrese V, Mancuso C. Ferulic acid and its therapeutic potential as a hormetin for age-related diseases. Biogerontology. (2009) 10:97-108. doi: 10.1007/s10522-008-9160-8

11. Balasubashini MS, Rukkumani R, Viswanathan P, Menon VP. Ferulic acid alleviates lipid peroxidation in diabetic rats. Phytother Res. (2004) 18:310-4. doi: $10.1002 /$ ptr.1440 vasculature. No information is available to get direct evidence of increasing nitric oxide from eNOS system or increasing the eNOS both in protein and mRNA level. Another noticeable research area would be the cardiac structure and function. Few experimental results were found whether ferulic acid modulates left ventricular dysfunction and hypertrophy of heart both in human and animal study. Metabolic syndrome and vascular dysfunction are also observed in many of the obese and diabetes patients. Ferulic acid has the potential to improve glucose disposal and metabolic syndrome (11). Moreover, ferulic acid lowered the plasma lipids in experimental animal $(11,34)$. However, no information is still available about the beneficial effect of ferulic acid on cardiovascular function in metabolic syndrome.

\section{CONCLUSION}

As discussed in this review, most of the beneficial effect of ferulic acid is due to its antioxidant and anti-inflammatory activities. However, the potential use of supplemental ferulic acid in the therapy of age-related human pathologies is still to be confirmed.

\section{AUTHOR CONTRIBUTIONS}

The author confirms being the sole contributor of this work and has approved it for publication.
12. Jung EH, Kim SR, Hwang IK, Ha TY. Hypoglycemic effects of a phenolic acid fraction of rice bran and ferulic acid in C57BL/KsJ-db/db mice. J Agric Food Chem. (2007) 55:9800-4. doi: 10.1021/jf0714463

13. Seal CJ. Whole grains and CVD risk. Proc Nutr Soc. (2006) 65:24-34. doi: 10.1079/PNS2005482

14. Scalbert A, Williamson G. Dietary intake and bioavailability of polyphenols. J Nutr. (2000) 130:2073S-85S. doi: 10.1093/jn/130.8.2073S

15. Beecher GR. Nutrient content of tomatoes and tomato products. Proc Soc Exp Biol Med. (1998) 218:98-100. doi: 10.3181/00379727-218-44282a

16. Tada Y, Tayama K, Aoki N. Acute oral toxicity of ferulic acid, natural food additive, in rats. Ann Rep Tokyo Metr Lab PH. (1999) 50:311-3.

17. Maurya DK, Devasagayam TPA. Antioxidant and prooxidant nature of hydroxycinnamic acid derivatives ferulic and caffeic acids. Food Chem Toxicol. (2010) 48:3369-73. doi: 10.1016/j.fct.2010.09.006

18. Ou L, Kong LY, Zhang XM, Niwa M. Oxidation of ferulic acid by Momordica charantia peroxidase and related anti-inflammation activity changes. Biol Pharm Bull. (2003) 26:1511-6. doi: 10.1248/bpb.26.1511

19. Yeh C-T, Ching L-C, Yen G-C. Inducing gene expression of cardiac antioxidant enzymes by dietary phenolic acids in rats. J Nutr Biochem. (2009) 20:163-71. doi: 10.1016/j.jnutbio.2008.01.005

20. Jin Son M, Rico CW, Hyun Nam S, Young Kang M. Influence of oryzanol and ferulic Acid on the lipid metabolism and antioxidative status in high fat-fed mice. J Clin Biochem Nutr. (2010) 46:150-6. doi: 10.3164/jcbn.09-98

21. Scapagnini G, Butterfield DA, Colombrita C, Sultana R, Pascale A, Calabrese V. Ethyl ferulate, a lipophilic polyphenol, induces HO-1 and protects rat neurons against oxidative stress. Antioxid Redox Signal. (2004) 6:811-8. doi: 10.1089/1523086041798079

22. Scapagnini G, Foresti R, Calabrese V, Stella AMG, Green CJ, Motterlini R. Caffeic acid phenethyl ester and curcumin: a novel class of heme oxygenase-1 inducers. Mol Pharmacol. (2002) 61:554-61. doi: 10.1124/mol.61.3.554

23. Motterlini R, Foresti R, Bassi R, Green CJ. Curcumin, an antioxidant and anti-inflammatory agent, induces heme oxygenase- 1 and protects endothelial 
cells against oxidative stress. Free Radic Biol Med. (2000) 28:1303-12. doi: 10.1016/S0891-5849(00)00294-X

24. Walsh LJ. Mast cells and oral inflammation. Crit Rev Oral Biol Med. (2003) 14:188-98. doi: 10.1177/154411130301400304

25. Sakai S, Kawamata H, Kogure T, Mantani N, Terasawa K, Umatake M, et al. Inhibitory effect of ferulic acid and isoferulic acid on the production of macrophage inflammatory protein-2 in response to respiratory syncytial virus infection in RAW264.7 cells. Mediators Inflamm. (1999) 8:173-5. doi: 10.1080/09629359990513

26. Kim EO, Min KJ, Kwon TK, Um BH, Moreau RA, Choi SW. Antiinflammatory activity of hydroxycinnamic acid derivatives isolated from corn bran in lipopolysaccharide-stimulated Raw 264.7 macrophages. Food Chem Toxicol. (2012) 50:1309-16. doi: 10.1016/j.fct.2012.02.011

27. Tetsuka T, Baier LD, Morrison AR. Antioxidants inhibit interleukin-1induced cyclooxygenase and nitric-oxide synthase expression in rat mesangial cells. Evidence for post-transcriptional regulation. J Biol Chem. (1996) 271:11689-93. doi: 10.1074/jbc.271.20.11689

28. Ohnishi M, Matuo T, Tsuno T, Hosoda A, Nomura E, Taniguchi H, et al. Antioxidant activity and hypoglycemic effect of ferulic acid in STZ-induced diabetic mice and KK-Ay mice. BioFactors. (2004) 21:315-9. doi: 10.1002/biof.552210161

29. Ronchetti D, Impagnatiello F, Guzzetta M, Gasparini L, Borgatti M, Gambari $\mathrm{R}$, et al. Modulation of iNOS expression by a nitric oxide-releasing derivative of the natural antioxidant ferulic acid in activated RAW 264.7 macrophages. Eur J Pharmacol. (2006) 532:162-9. doi: 10.1016/j.ejphar.2005.12.034

30. Sudheer AR, Muthukumaran S, Devipriya N, Devaraj H, Menon VP. Influence of ferulic acid on nicotine-induced lipid peroxidation, DNA damage and inflammation in experimental rats as compared to $\mathrm{N}$-acetylcysteine. Toxicology. (2008) 243:317-29. doi: 10.1016/j.tox.2007.10.016

31. Sri Balasubashini M, Rukkumani R, Menon VP. Protective effects of ferulic acid on hyperlipidemic diabetic rats. Acta Diabetol. (2003) 40:118-22. doi: 10.1007/s00592-003-0099-6

32. Adisakwattana S, Moonsan P, Yibchok-Anun S. Insulin-releasing properties of a series of cinnamic acid derivatives in vitro and in vivo. J Agric Food Chem. (2008) 56:7838-44. doi: 10.1021/jf801208t

33. Ohara K, Uchida A, Nagasaka R, Ushio $H$, Ohshima T. The effects of hydroxycinnamic acid derivatives on adiponectin secretion. Phytomedicine. (2009) 16:130-7. doi: 10.1016/j.phymed.2008.09.012

34. Ardiansyah, Ohsaki Y, Shirakawa H, Koseki T, Komai M. Novel effects of a single administration of ferulic acid on the regulation of blood pressure and the hepatic lipid metabolic profile in stroke-prone spontaneously hypertensive rats. J Agric Food Chem. (2008) 56:2825-30. doi: 10.1021/jf072896y

35. Andreasen MF, Landbo AK, Christensen LP, Hansen A, Meyer AS. Antioxidant effects of phenolic rye (Secale cereale L.) extracts, monomeric hydroxycinnamates, and ferulic acid dehydrodimers on human low-density lipoproteins. J Agric Food Chem. (2001) 49:4090-6. doi: 10.1021/jf0101758

36. Kwon EY, Do GM, Cho YY, Park YB, Jeon SM, Choi MS. Anti-atherogenic property of ferulic acid in apolipoprotein E-deficient mice fed Western diet: comparison with clofibrate. Food Chem Toxicol. (2010) 48:2298-303. doi: $10.1016 /$ j.fct.2010.05.063

37. Yogeeta SK, Hanumantra RB, Gnanapragasam A, Senthilkumar S, Subhashini R, Devaki T. Attenuation of abnormalities in the lipid metabolism during experimental myocardial infarction induced by isoproterenol in rats: beneficial effect of ferulic acid and ascorbic acid. Basic Clin Pharmacol Toxicol. (2006) 98:467-72. doi: 10.1111/j.1742-7843.2006.pto_335.x

38. Fujita A, Sasaki H, Doi A, Okamoto K, Matsuno S, Furuta H, et al. Ferulic acid prevents pathological and functional abnormalities of the kidney in Otsuka Long-Evans Tokushima Fatty diabetic rats. Diabetes Res Clin Pract. (2008) 79:11-7. doi: 10.1016/j.diabres.2007.08.009

39. Suzuki A, Kagawa D, Fujii A, Ochiai R, Tokimitsu I, Saito I. Short- and longterm effects of ferulic acid on blood pressure in spontaneously hypertensive rats. Am J Hypertens. (2002) 15:351-7. doi: 10.1016/S0895-7061(01)02337-8

40. Cooke M, John P., Dzau M, Victor J. NITRIC OXIDE SYNTHASE: role in the genesis of vascular disease. Annu Rev Med. (1997) 48:489-509. doi: 10.1146/annurev.med.48.1.489

41. Behrendt D, Ganz P. Endothelial function: from vascular biology to clinical applications. Am J Cardiol. (2002) 90(10 Suppl. 3):L40-8. doi: 10.1016/S0002-9149(02)02963-6
42. Taniyama Y, Griendling KK. Reactive oxygen species in the vasculature. Hypertension. (2003) 42:1075-81. doi: 10.1161/01.HYP.0000100443.09293.4F

43. Touyz RM, Schiffrin EL. Reactive oxygen species in vascular biology: implications in hypertension. Histochem Cell Biol. (2004) 122:339-52. doi: 10.1007/s00418-004-0696-7

44. Paravicini TM, Touyz RM. NADPH oxidases, reactive oxygen species, and hypertension. Diabetes Care. (2008) 31(Suppl. 2):S170-80. doi: $10.2337 / \mathrm{dc} 08$-s 247

45. Suzuki A, Yamamoto M, Jokura H, Fujii A, Tokimitsu I, Hase T, et al. Ferulic acid restores endothelium-dependent vasodilation in aortas of spontaneously hypertensive rats. Am J Hypertens. (2007) 20:508-13. doi: 10.1016/j.amjhyper.2006.11.008

46. Chen GP, Ye Y, Li L, Yang Y, Qian AB, Hu SJ. Endothelium-independent vasorelaxant effect of sodium ferulate on rat thoracic aorta. Life Sci. (2009) 84:81-8. doi: 10.1016/j.lfs.2008.11.003

47. Alexander RW. Hypertension and the pathogenesis of atherosclerosis: oxidative stress and the mediation of arterial inflammatory response: a new perspective. Hypertension. (1995) 25:155-61. doi: 10.1161/01.HYP.25. 2.155

48. Gorenne I, Bennett MR. Oxidative stress in vascular disease aging and agerelated disorders. In: Bondy S, Maiese K, editors. Oxidative Stress in Applied Basic Research and Clinical Practice. Humana Press (2010). p. 211-35.

49. Garg UC, Hassid A. Nitric oxide-generating vasodilators and 8-bromocyclic guanosine monophosphate inhibit mitogenesis and proliferation of cultured rat vascular smooth muscle cells. J Clin Invest. (1989) 83:1774-7. doi: 10.1172/JCI114081

50. Hou YZ, Yang J, Zhao GR, Yuan YJ. Ferulic acid inhibits vascular smooth muscle cell proliferation induced by angiotensin II. Eur J Pharmacol. (2004) 499:85-90. doi: 10.1016/j.ejphar.2004.07.107

51. Zalba G, Beaumont FJ, José GS, Fortuño A, Fortuño MA, Etayo JC, et al. Vascular NADH/NADPH oxidase is involved in enhanced superoxide production in spontaneously hypertensive rats. Hypertension. (2000) 35:105561. doi: 10.1161/01.HYP.35.5.1055

52. Zhang Y, Griendling KK, Dikalova A, Owens GK, Taylor WR. Vascular hypertrophy in angiotensin II-induced hypertension is mediated by vascular smooth muscle cell-derived H2O2. Hypertension. (2005) 46:732-7. doi: 10.1161/01.HYP.0000182660.74266.6d

53. Beswick RA, Dorrance AM, Leite R, Webb RC. NADH/NADPH oxidase and enhanced superoxide production in the mineralocorticoid hypertensive rat. Hypertension. (2001) 38:1107-11. doi: 10.1161/hy1101.093423

54. Kanegae MPP, da Fonseca LM, Brunetti IL, de Oliveira Silva S, Ximenes VF. The reactivity of ortho-methoxy-substituted catechol radicals with sulfhydryl groups: contribution for the comprehension of the mechanism of inhibition of NADPH oxidase by apocynin. Biochem Pharmacol. (2007) 74:457-64. doi: 10.1016/j.bcp.2007.05.004

55. Actis-Goretta L, Ottaviani JI, Fraga CG. Inhibition of angiotensin converting enzyme activity by flavanol-rich foods. J Agric Food Chem. (2006) 54:229-34. doi: $10.1021 / \mathrm{jf} 052263 \mathrm{o}$

56. Roux PP, Blenis J. ERK and p38 MAPK-activated protein kinases: a family of protein kinases with diverse biological functions. Microbiol Mol Biol Rev. (2004) 68:320-44. doi: 10.1128/MMBR.68.2.320-344.2004

57. Johnson GL, Lapadat R. Mitogen-activated protein kinase pathways mediated by ERK, JNK, and p38 protein kinases. Science. (2002) 298:1911-2. doi: $10.1126 /$ science. 1072682

58. Touyz RM, Tabet F, Schiffrin EL. Redox-dependent signalling by angiotensin II and vascular remodelling in hypertension. Clin Exp Pharmacol Physiol. (2003) 30:860-6. doi: 10.1046/j.1440-1681.2003.03930.x

59. Montezano AC, Callera GE, Yogi A, He Y, Tostes RC, He G, et al. Aldosterone and angiotensin II synergistically stimulate migration in vascular smooth muscle cells through c-Src-regulated redox-sensitive RhoA pathways. Arterioscler Thromb Vasc Biol. (2008) 28:1511-8. doi: 10.1161/ATVBAHA.108.168021

60. Nicholson SK, Tucker GA, Brameld JM. Effects of dietary polyphenols on gene expression in human vascular endothelial cells. Proc Nutr Soc. (2008) 67:42-7. doi: $10.1017 /$ S0029665108006009

61. Sahu R, Dua TK, Das S, De Feo V, Dewanjee S. Wheat phenolics suppress doxorubicin-induced cardiotoxicity via inhibition of oxidative stress, MAP kinase activation, NF-kappaB pathway, PI3K/Akt/mTOR 
impairment, and cardiac apoptosis. Food Chem Toxicol. (2019) 125:503-19. doi: 10.1016/j.fct.2019.01.034

62. Lin TY, Lu CW, Huang SK, Wang SJ. Ferulic acid suppresses glutamate release through inhibition of voltage-dependent calcium entry in rat cerebrocortical nerve terminals. J Med Food. (2013) 16:112-9. doi: 10.1089/jmf. 2012.2387

63. Asano T, Matsuzaki H, Iwata N, Xuan M, Kamiuchi S, Hibino Y, et al. Protective effects of ferulic acid against chronic cerebral hypoperfusioninduced swallowing dysfunction in rats. Int J Mol Sci. (2017) 18:550. doi: 10.3390/ijms18030550

64. Baek SE, Kim JY, Song WT, Lee SH, Hong JH, Lee CK, et al. Neuroprotective effect of rice bran extract supplemented with ferulic acid in the rat model of ischemic brain injury. Anim Cells Syst. (2014) 18:93-100. doi: 10.1080/19768354.2014.904249

65. Cheng CY, Ho TY, Lee EJ, Su SY, Tang NY, Hsieh CL. Ferulic acid reduces cerebral infarct through its antioxidative and anti-inflammatory effects following transient focal cerebral ischemia in rats. Am J Chin Med. (2008) 36:1105-19. doi: 10.1142/S0192415X08006570

66. Ren Z, Zhang R, Li Y, Li Y, Yang Z, Yang H. Ferulic acid exerts neuroprotective effects against cerebral ischemia/reperfusion-induced injury via antioxidant and anti-apoptotic mechanisms in vitro and in vivo. Int J Mol Med. (2017) 40:1444-56. doi: 10.3892/ijmm.2017.3127
67. Cheng C-Y, Tang N-Y, Kao S-T, Hsieh C-L. Ferulic Acid administered at various time points protects against cerebral infarction by activating p38 MAPK/p90RSK/CREB/Bcl-2 anti-apoptotic signaling in the subacute phase of cerebral ischemia-reperfusion injury in rats. PLoS ONE. (2016) 11:e0155748. doi: 10.1371/journal.pone.0155748

68. Dalkara T, Moskowitz MA. The complex role of nitric oxide in the pathophysiology of focal cerebral ischemia. Brain Pathol. (1994) 4:49-57. doi: 10.1111/j.1750-3639.1994.tb00810.x

69. Koh PO. Ferulic acid modulates nitric oxide synthase expression in focal cerebral ischemia. Lab Anim Res. (2012) 28:273-8. doi: 10.5625/lar.2012.28.4.273

Conflict of Interest Statement: The author declares that the research was conducted in the absence of any commercial or financial relationships that could be construed as a potential conflict of interest.

Copyright (C) 2019 Alam. This is an open-access article distributed under the terms of the Creative Commons Attribution License (CC BY). The use, distribution or reproduction in other forums is permitted, provided the original author(s) and the copyright owner(s) are credited and that the original publication in this journal is cited, in accordance with accepted academic practice. No use, distribution or reproduction is permitted which does not comply with these terms. 